\title{
Uma odisséia de vanguarda: internacionalismo e resistência no projeto português da poesia experimental
}

Rogério Barbosa da Silva Centro Federal de Educação Tecnológica de Minas Gerais

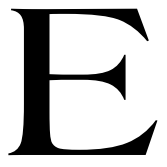

mbora já decorridos cerca de 45 anos e seus autores tenham constituído uma produção poética e crítica sólida na literatura portuguesa, a Poesia Experimental Portuguesa tem sido tratada ainda com um certo desinteresse pela crítica literária, com raríssimas exceções, como se pode notar na recente Antologia da Poesia Experimental Portuguesa - Anos 60/70, organizada por Carlos Mendes Sousa e Eunice Ribeiro, lançada ao final de janeiro de 2005 e que contém, ainda, um importante estudo introdutório sobre o movimento português. A este, devemos acrescentar também outros volumes como o excelente trabalho oriundo de uma tese de mestrado de Pedro Reis, Poesia Concreta: uma prática intersemiótica (1998) e a antologia Interfaces do olhar (2004), com ensaios de vários autores sobre a poética de Ana Hatherly e uma seleção de poemas da autora. Apesar dessas mudanças já significativas no quadro da crítica e da historiografia, é ainda relevante assinalar o papel de abertura estética que a poesia experimental agenciou, promovendo a ruptura com o establishment cultural e político da época em prol da inovação. Para isso, os poetas ligados ao experimentalismo procuraram se conectar a rede internacional que se organizava, então, em torno da Poesia Concreta, de modo a romper o isolamento político e a estimular a inovação estética em curso em vários países, tendo a poesia brasileira como uma das pontas desta meada.

Considerado este contexto, quando a Poesia Concreta brasileira chega a Portugal, obviamente já dominavam, no cenário literário português, uma inquietação e uma busca de expressão poética nova, que 
pode ser assinalada desde o início dos anos 50. De um modo geral, a situação ali não foi diferente daquele quadro estagnante encontrado na poesia brasileira, com a geração de 45, ou na Suíça de Eugen Gomringer, durante o pós-guerra, países em que se desenvolveria a Poesia Concreta. Assim, os escritores portugueses mais jovens também perceberam, no experimentalismo poético, a coincidência de um projeto que evidenciava um explícito desejo de mudanças tanto no plano estético quanto no político-social.

Essa arrancada para as mudanças, em Portugal, poderia ser situada a partir dos grupos que, nos anos 50, reuniram-se em torno das revistas Távola Redonda, Árvore e do Movimento Surrealista, todos reagindo às estéticas presencista e neo-realista dominantes. Seu ápice seria a eclosão de duas tendências oriundas do que se chamou Poesia 61 (reunindo Casimiro de Brito, Fiama Hasse Pais Brandão, Gastão Cruz, Luiza Neto Jorge e Maria Tereza Horta) e dos Cadernos da Poesia Experimental (n. I, 1964 e n. II, 1966), liderados por Herberto Helder, António Aragão e E. M. Melo e Castro. Essas seriam as linhas de força que, segundo Melo e Castro, configurariam a inovação na poesia portuguesa durante os anos de 50 e $60^{1}$.

Fernando Guimarães, porém, em Poesia portuguesa contemporânea e o fim da modernidade (1989), recua o início dessa renovação aos anos 40, com poetas como Rui Cinatti, Sophia de Melo Breyner Andresen, Jorge de Sena, Eugênio de Andrade e Carlos Oliveira, apesar da ligação deste último com os neo-realistas. O que caracterizaria essa poesia seria a mudança de uma discursividade expansiva, ideológica ou confessional para um adensamento essencial do discurso poético. Ao rastrear, na obra desses poetas, aquilo que representaria uma abertura para a ruptura realizada por "Poesia 61" e pelas "poesias concreta e poesia experimental" dos anos 60, Fernando Guimarães indica a gradativa construção de uma poética que privilegiaria "a forma gravada em vazio", "o puro branco", "o fragmento", "o sentido de uma depuração". Segundo o autor, poderíamos

(...) dizer que tanto a Poesia Concreta como os poetas que se reúnem em torno de Poesia 61 tinham em vista aquilo que tantas vezes se designou por "autonomia da palavra", o que representa a procura de uma linguagem que, num ou noutro caso, se torna fundamentalmente

\footnotetext{
${ }^{1}$ Cf. CASTRO, 1973, p. 28-42.
} 
substantiva. No entanto, o movimento da Poesia Concreta pretendeu levar mais longe essa procura, o que não deve espantar-nos se tivermos presente a circunstância de ele se reclamar de um movimento de vanguarda. Animado por esse propósito, acabará por pôr em questão a chamada "escrita analítica" que preside ao "poema escrito alfabeticamente” para, a partir de uma nova organização, valorizar sobretudo as componentes verbal e visual. (...) Quanto a este empenho de seleção [vocabulário mínimo artisticamente escolhido - Poesia Concreta], algo semelhante se passa com a Poesia 61, preocupada em conter a dispersão verbal para que tendiam certos movimentos anteriores, como os da Presença, do Neo-realismo e do Surrealismo ${ }^{2}$.

Os traços notados por Fernando Guimarães na poesia portuguesa dos anos 60 são extremamente interessantes, porque indicam que tanto Poesia 61 quanto Poesia Experimental almejaram a construção de uma poética da ruptura com tradições poéticas imediatamente anteriores. $\mathrm{O}$ experimentalismo português, como lembram Carlos Mendes Sousa e Eunice Ribeiro, fez-se

declaradamente sob o signo do antidiscurso e da contracultura. Um antidiscurso que parecia pretender transgredir, antes de mais, um secular 'culto dos conteúdos' e de toda a filosofia de arquétipos que lhe serviu de pano de fundo para propor uma revolucionária e provocatória poesia 'de formas'3.

A ação crítica, francamente de esquerda, adotada pelos poetas da poesia experimental talvez tenha também acionado a pressão política do regime de Salazar, assim como a transgressão ao "culto dos conteúdos" projetaria a poesia experimental para um espaço marginal ainda persistente. Daí, talvez, haver subsistido um sentimento de "protesto vanguardista" datado. Embora a análise de Fernando Guimarães não reflita nenhuma ligação com as questões político-ideológicas, esse é um período em que havia censura salazarista, um tema que ainda hoje perpassa a ficção portuguesa contemporânea. Além disso, o experimentalismo coincidia tanto com a revolução sócio-política e cultural dos anos 60 quanto com o início da guerra colonial, e o fechamento provinciano

\footnotetext{
${ }^{2}$ GUIMARÃES, 1989, p. 102.

${ }^{3}$ SOUSA \& RIBEIRO, 2004, p. 30.
} 
lançado pelo Estado Novo. Nesse sentido, pode ser notada uma pressão política sobre movimentos poéticos alternativos tanto por parte daqueles que prezavam conteudismo esquerdista quanto por parte do regime de Salazar, aproximando, assim, os surrealistas e os experimentalistas como opositores ao status quo, ou como inimigos do regime por meio de sua proposta de integração ao movimento internacional e por seus textos bastante provocativos para a ordem estabelecida. Ana Hatherly e Melo e Castro afirmam várias vezes, tanto nas entrevistas que nos concederam quanto em alguns de seus textos críticos, que a poesia experimental e a Poesia Concreta insurgiam-se contra o establishment intelectual e político daquele período. Carlos Mendes Sousa e Eunice Ribeiro referem-se a esta questão na "Introdução" a sua Antologia da Poesia Experimental Portuguesa - anos 60-anos 80:

A cronologia desta primeira fase - "polêmica" - do experimentalismo português, que coincide praticamente com toda a década de 60 , em pleno regime ditatorial, instigou certamente um tipo de postura esteticamente tolerante e "aberta" que por si funcionava já como um gesto urgente de ruptura. Nos textos documentais sobre a PO.EX nacional, acentua-se vigorosamente a necessidade de "rebelião", de "ação violenta", "a necessidade do NÃO, como o coloca Melo e Castro, contra o status quo vigente, contra a política censória, contra a arte e a crítica oficiais ${ }^{4}$.

Carlos Sousa e Eunice Ribeiro assinalam ainda que os cadernos de Poesia Experimental foram o órgão visível dessa ruptura, cujos propósitos

de desmistificação dos discursos 'retrógrados' do poder instituído passavam pela adesão às inovações formais e visuais da Poesia Concreta e pela assimilação inusual da tradição literária que justificava a inclusão de uma seção antológica, no primeiro número da revista, preenchida com autores nacionais e estrangeiros, como Camões, Ângelo de Lima, Cesariny de Vasconcelos, o italiano Emilio Villa e o poeta barroco alemão Quirinus Kuhlmann 5 .

Como se vê nessa reflexão de Sousa e Ribeiro, a ligação do experimentalismo português com o surrealismo é, pelo menos ambígua.

\footnotetext{
${ }^{4}$ SOUSA \& RIBEIRO, 2004, p. 43.

5 SOUSA \& RIBEIRO, 2004, p. 43-4.
} 
Por um lado, como afirmou Fernando Guimarães no excerto anteriormente transcrito, os experimentalistas procuravam "conter a dispersão verbal". Por outro, verificamos que, além de os experimentalistas valorizarem a atitude não conformista e politicamente ativa dos surrealistas, eles destacam também a dimensão espacial da obra de alguns desses autores. Por exemplo, na edição do volume Antologia da Poesia Concreta portuguesa (1973), organizado por E. M. de Melo e Castro e José Alberto Marques, são incluídos também poemas que contêm grafismos de poetas como Jaime Salazar Sampaio, mais próximos de surrealistas, como Alexandre O'Neill e referências a Mário Cesarini de Vasconcelos (que não consta da antologia, mas produziu poesia visual, às vezes referida por Castro). Segundo os autores, uma antologia de Poesia Concreta com autores tão heterogêneos pode ser justificada pelo fato de que, em Portugal, nunca se chegou a constituir um grupo organizado de poetas concretos $^{6}$. Desse modo, poderiam ser assinalados exemplos esporádicos de poemas que seguem uma coordenada visual e uma organização tipográfica planejadas na página, sendo que estes procedimentos são vistos pelos organizadores como indícios da pesquisa morfo-semântica dos experimentalismos subseqüentes. Exemplos interessantes desse contato entre as duas versões de experimentalismos são os poemas de Alexandre O'Neill, António Aragão e Ana Hatherly, respectivamente, o surrealista, o idealizador dos Cadernos da Poesia Experimental e uma de suas principais expoentes:

${ }^{6}$ Cf. MARQUES \& CASTRO, 1973, p. 11. 
Exemplo 1 - Alexandre O'Neill "Opressão" e "Delongas"7

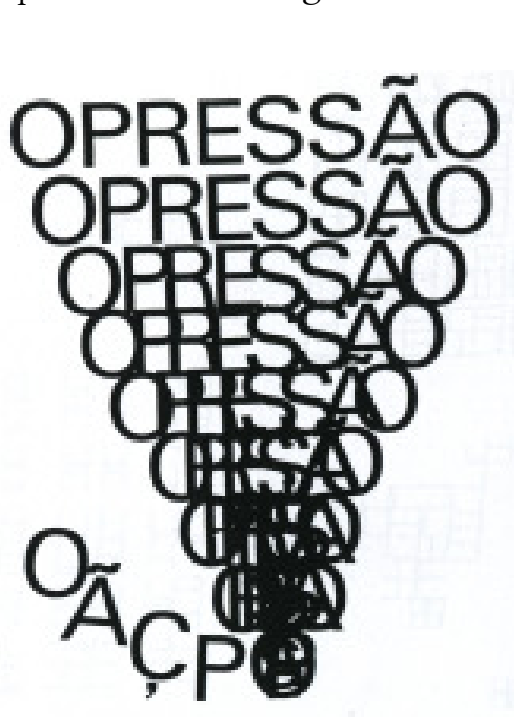

Doreanss - Alesandre OVhell - Igr2

coneess

incosing

timesones.

oleenser.

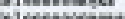

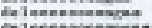

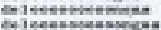

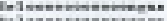

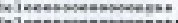

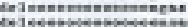

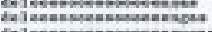

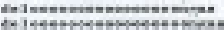

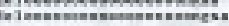

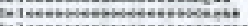

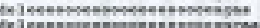

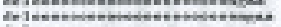

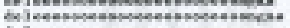

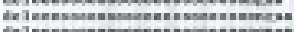

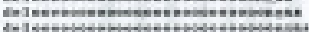

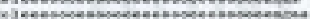

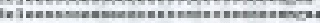

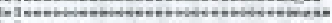

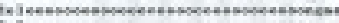

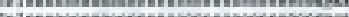

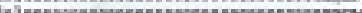

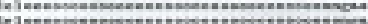

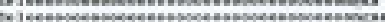

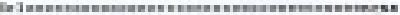

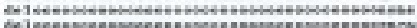
CQ

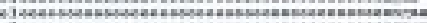

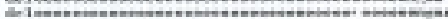

Podemos observar que "opressão" e "delongas" são poemas que redundam, visualmente, a mensagem "prevista" pelos significantes utilizados, uma vez que oprimir implica o aniquilamento ou a coação sobre o sujeito; daí que a compressão exercida no próprio significante, pela sobreposição das letras, possibilita a realização de um dos significados possíveis à palavra. No entanto, o ato de esmagamento sugere a explosão que resulta numa saída, implícita na palavra "opção" - a implicação de uma escolha. Noutras palavras, o poema realiza a abertura da significação pela utilização de uma visualidade que leva à concretização

\footnotetext{
${ }^{7}$ In: CASTRO \& MARQUES, 1973, p. 32-3.
} 
de uma idéia abstrata. É um procedimento semelhante ao do poema "delongas", que, estruturalmente, explicita a idéia de "demora" na configuração de um triângulo retângulo, com a base na vertical. À medida que o olhar do leitor desce em direção ao ângulo reto, há uma sugestão de estagnação e de maior adiamento de uma saída (de uma provável situação de angústia, de ansiedade, de opressão, etc.), porque a palavra vai sendo alongada na direção horizontal. Assim, ao contrário de "opressão", não se vislumbra uma saída, mas um modo de alerta, que se aprende didaticamente pela visualidade.

São poemas que se utilizam unicamente de palavras e as interferências ou desintegrações visam à produção de sentido, como num texto tradicional. Trata-se, no entanto, de uma poesia concisa e atenta a outros modos de configuração desse sentido. Vejamos os poemas de António Aragão e Ana Hatherly:

Exemplo 2 - António Aragão - "Antes de vós ${ }^{8}$

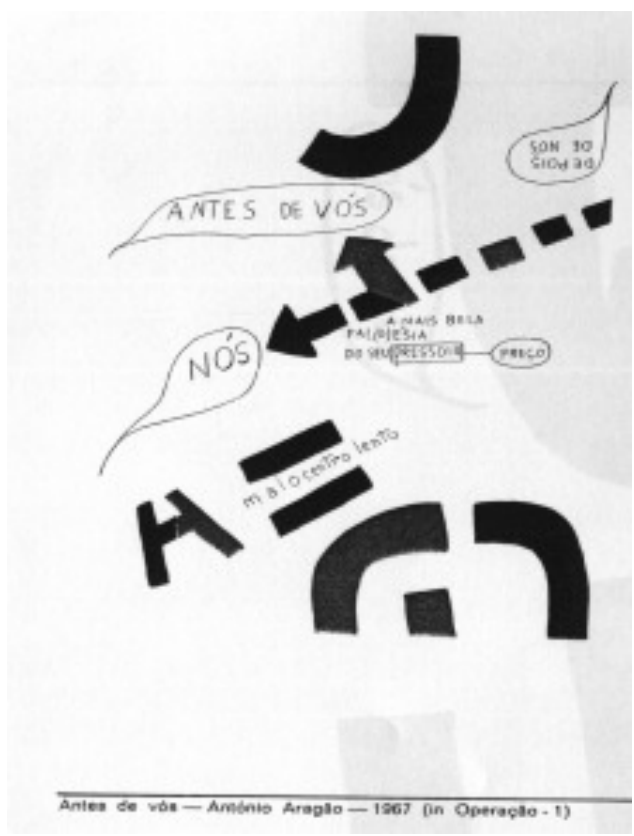

${ }^{8}$ In: CASTRO \& MARQUES, 1973, p. 46. 
O exemplo seguinte é um dos trabalhos de Ana Hatherly, que estabelece uma tensão entre a escrita e a imagem:

Exemplo 3 - Ana Hatherly - "Inédito" (1971) 9

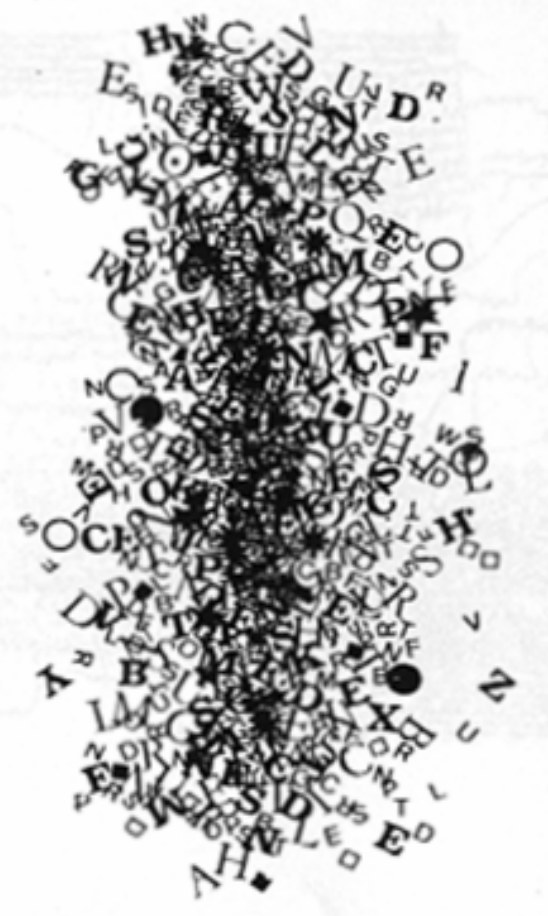

Nestes exemplos, tanto de António Aragão quanto de Ana Hatherly, a palavra não é utilizada para estabelecer um discurso: ou ela se desintegra, ou produz sentido na conjunção com outros códigos, de modo abertamente antidiscursivo. Desse modo, os poemas do grupo nuclear da Poesia Experimental Portuguesa propõem uma experimentação que está mais próxima de algumas realizações do Poema-Processo brasileiro,

\footnotetext{
${ }^{9}$ In: CASTRO \& MARQUES, 1973, p. 40.
} 
devido à fusão de códigos e linguagens diversos, no sentido de uma funcionalidade estrutural. Marcas lingüísticas, como os pronomes e os articuladores, como os advérbios, não sugerem, aqui, um discurso nascido de uma explosão de subjetividade; a força do texto está na desagregação e na convocação para uma nova configuração da leitura. Nesse sentido, manifesta-se a abertura do texto de António Aragão, que propõe um deslizamento por entre os códigos verbal e não-verbal. Não há possibilidades, assim, de uma leitura tradicional, decifratória. Tal como acontece na poesia de Ana Hatherly, esse poema de Aragão parece buscar a impossibilidade da leitura, de modo que o ilegível se transforme numa poética. No texto de Ana Hatherly, o ilegível é representado através da rasura, do borrão. Em certos aspectos, o trabalho que se faz pela intercodificação, em geral se permitindo uma ação metalingüística que age sobre a escrita, leva-nos a pensar que são atos poéticos bem próximos das descobertas sensoriais dos surrealistas, uma vez que convocam a participação dos nossos cinco sentidos.

Evidentemente parece descontextualizada uma antologia de Poesia Concreta que contenha poemas concebidos dentro de padrões surrealistas, mas é preciso lembrar que esses surrealistas portugueses são um tanto quanto tardios (O Surrealismo chegou oficialmente a Portugal em 1949). Da mesma forma, também os poetas concretos brasileiros demonstraram interesse pela poesia simbolista radicalizada por Mallarmé e por Rimbaud, os quais traduziram. O que os concretos buscaram nesses autores foi a inventividade de sua poesia, aquilo que escapava às convenções do próprio simbolismo, ou seja, uma linguagem que, ao exacerbar o poder de sugestão, conduz o texto para as dimensões espaciais ou musicais não-representativas. Não é outra coisa o que vêem os "concretos" portugueses nos poemas de Cesariny, O'Neil e Salazar Sampaio, de quem são, sobretudo, contemporâneos.

Melo e Castro explica que o Surrealismo chegou, tardiamente, a Portugal por importação, a partir da obra de António Pedro. No pósguerra, por encontrar no país, um meio propício, ele se teria transplantado de uma forma original e eficaz, assumindo seu estatuto de vanguarda, em particular a partir das exposições de 1949 e 1952. Melo e Castro atribui originalidade à formulação do "voluntarismo" por António Pedro no texto "Por que sou surrealista", publicado no catálogo da Exposição Surrealista de 1949. Segundo Castro, com o "voluntarismo", António Pedro conjuga inovação e revolução, ao frisar que "o encontro com a liberdade tem a 
vantagem de ser inconveniente para tudo o que não é conveniente." ${ }^{10}$. A idéia de que é preciso ser "inconveniente" perpassa muitos textos críticos da poesia experimental, uma vez que seus autores criticam com vigor o clima de opressão e a estreiteza de idéias. Por isso mesmo a proposta de António Pedro será vista por Melo e Castro como um misto de intuição e razão, simbolismo fantástico e construtivismo. Assim, o Surrealismo português será valorizado pelo experimentalismo, por possuir também uma dimensão de vanguarda:

O Surrealismo é, por isso [por sua função de resistência e denúncia], inventivo e amaldiçoado, ou seja, reconhecido implicitamente com a vanguarda típica dos anos 40 e começo da década de 50. A sua prática vai assim desde a ação ética de denúncia inconformista, passando por uma espécie de boemia tipicamente lisboeta (Grupo do Café Gelo) até às práticas ocultistas (António Maria Lisboa) até à inovação textual (Mário Cesariny), ou até ao humor como prática textual, ligado aos poetas sarcásticos, facetos e conceptistas (em Alexandre O'Neill), constituindo uma espécie de underground em que o modo de assumir a pequenez e o nojo da vida política e cultura portuguesa se transforma, com o aparecimento de uma nova geração de surrealistas, no Abjeccionismo, que é uma forma de satanismo surrealista, contrapondose a um certo angelismo que era caro a André Breton. ${ }^{11}$

A própria poesia experimental será vista como uma espécie de "underground", segundo os autores da Po.ex. Por isso, pode-se concluir que havia um objetivo comum entre os surrealistas e os poetas que viriam a ser chamados de experimentalistas, pois os dois grupos buscavam constituir-se como vanguarda e desejavam sacudir o ambiente cultural da época. No plano estético, os surrealistas também deixaram algumas marcas na obra dos experimentalistas, mesmo na dos mais rigorosos, como Melo e Castro. Ele denominou Hidra (uma palavra que soaria bem a um decadentista ou mesmo surrealista) uma revista literária que fundou em 1966. Esta revista contou apenas com dois números, que hoje são raridades, mesmo nas bibliotecas especializadas portuguesas. Um aspecto relevante da revista é a busca de colaboradores entre poetas que vinham de Poesia 61, como Fiama Hasse Pais Brandão, Luísa Neto Jorge, Gastão

\footnotetext{
${ }^{10}$ Apud CASTRO, 1987, p. 65.

${ }^{11}$ CASTRO, 1987, p. 66-67.
} 
Cruz, e poetas dos Cadernos de Poesia Experimental. Tal colaboração constituiu, certamente, uma tentativa de aproximar as correntes que se transformaram em verdadeiros divisores de águas na poesia portuguesa.

A Poesia Experimental Portuguesa, conforme mencionamos anteriormente, acentuou deliberadamente a necessidade do "não", numa tentativa de desmistificação dos discursos do poder instituído. Isso é realmente importante para que possamos entender o quadro políticocultural complexo no qual será recepcionada a Poesia Concreta proveniente do Brasil, e em que se vai constituindo o próprio movimento da poesia experimental local. Dessa maneira, é preciso considerar que havia naquele período tanto a ação dos escritores neo-realistas quanto a censura política do Estado. Por um lado, os neo-realistas eram vigiados pelo regime de exceção, que acompanhava sua prática discursiva e ideológica; por outro, esses mesmos escritores exerciam pressão ideológica sobre os movimentos de vanguarda, contando com um solo mais firme devido à sua ascendência na poesia portuguesa por quase 40 anos - o "movimento" surgiu por volta de 1939, com a publicação de Gaibeus, de Alves Redol. Como afirmou Melo e Castro, em entrevista, os neo-realistas viam os experimentalistas com desconfiança, porque, conforme a perspectiva de Lukács, consideravam essa poesia degenerada. Assim, aos olhos dos neo-realistas, a poesia experimental ou concreta era uma ameaça; aos olhos do poder constituído e da perspectiva cultural da época, a Poesia Experimental representava uma poética outsider. Fernando Guimarães refere-se a esse problema, indicando que, a partir da década de 60, o neo-realismo português receberá uma segunda reformulação ao confrontarem a opção de vanguarda aberta pela Poesia Experimental, tal como ocorrera no confronto entre neo-realistas e surrealistas no início dos anos 50, quando estes colocaram o problema de uma certa autonomia da linguagem e o seu adensamento simbólico frente àquela poesia de "enraizamento" social e de conteúdo trazido pela primeira fase dos neo-realistas nos anos 40. Contra a suspeição das vanguardas, decorrente de releituras de Lukács, Fernando Guimarães procura mostrar que essa questão de a vanguarda ser oposta a um realismo crítico constitui uma discussão mais complexa, o que ele faz re-situando o experimentalismo a partir de discussões de Arnaldo Saraiva e de Alberto Pimenta. Assim, Guimarães expõe o problema do confronto entre essas duas correntes, deixando clara a posição do experimentalismo como poesia "outsider": 
O experimentalismo, enquanto atitude de vanguarda, representaria um confronto com qualquer poética normativa, a que o neo-realismo não deixaria de pertencer, sobretudo quando tal movimento intente ainda prender-se à teoria de arte de caráter dogmático, como, segundo Alberto Pimenta, é a de Lukács. A arte deveria romper esse círculo normativo, encontrando uma referência estética de natureza subjetiva, um espaço de anarquia expressiva, pelo qual, como nos diz, o artista se furtasse à 'apropriação do indivíduo pela sociedade'. Esta movimentação é paralela à própria desagregação ou erosão a que se sujeita o sentido, entendido este como vínculo que possibilita um entendimento interindividual ou social a um preço que é, afinal, o do aprisionamento do artista a essas categorias semânticas. A polivalência no campo do significado, a falta de um referencialismo ou de uma vinculação pragmática, a 'passagem de uma arte semântica a uma arte sintáctica', onde os símbolos são apenas sinais de si mesmos, parecem ser os caminhos de uma arte renovada, capaz de se assumir como vanguarda ou como uma atitude ainda mais radical e transgressora, a da contracultura. ${ }^{12}$

Como podemos verificar, tanto os experimentalistas quanto os neorealistas tinham um posicionamento de esquerda e eram, portanto, mal vistos pelo regime salazarista. Com o tempo, porém, as dissensões entre os experimentalistas e os neo-realistas diminuíram, pois estes últimos perceberam que a Poesia Experimental produzia uma leitura crítica da realidade, conforme observa Melo e Castro:

O que os neo-realistas queriam em Portugal era um simulacro de realidade antifascista. Eles, então, desferiam os golpes mais violentos, às vezes mais violentos que os fascistas. (...) Evidentemente, depois durante os anos 60, as coisas foram evoluindo, e eles perceberam que estávamos a fazer um trabalho que era contra o fascismo. Simplesmente, nós usávamos armas diferentes. O nosso posicionamento era na linguagem e na língua, mais até na língua que na linguagem, o nosso trabalho era um trabalho de desconstrução da linguagem oficial do fascismo português. E todos tivemos esse trabalho, o António Aragão, a Ana Hatherly, que se havia juntado a nós, a própria Salette [Tavares], o Ramos Rosa, os novos: José Alberto Marques, Silvestre Pestana, António Barros, todos partilhávamos desse trabalho na língua e na imagem $^{13}$.

\footnotetext{
${ }^{12}$ GUIMARÃES, 1989, p. 64.

${ }^{13}$ CASTRO, Apud SILVA, 2002, [s.p.].
} 
Esse quadro político-cultural é, porém muito mais complexo, reunindo uma diversidade de grupos e de propostas poéticas. Por exemplo, os grupos de poetas se reuniam em torno das várias revistas que, por sua vez, agrupavam diversas tendências políticas. A atividade política, no entanto, não impedia que os poetas superassem compromissos ideológicos e produzissem poesia de qualidade. Fernando Guimarães cita um exemplo clássico dessa superação na obra de Carlos de Oliveira, ligado ao grupo neo-realista, mas empenhado num processo de reformulação e de reelaboração de seus textos poéticos, com o que exercitou uma consciência crítica em termos de linguagem ${ }^{14}$. O crítico português alude também à passagem pacífica de Egito Gonçalves às experiências surrealistas na revista Notícias do Bloqueio, entre 1957 e 1962. Egito Gonçalves acompanhou, também, muitas iniciativas da poesia experimental, contribuindo com poemas para essas publicações. Dessa maneira, parecerá muitas vezes contraditório o impulso renovador que se descortina a partir dos anos 50, uma vez que o trânsito de alguns poetas por determinados grupos políticos e estéticos pode sugerir alguma idéia de retrocesso. Entretanto, não há retrocesso político ou estético na passagem "pacífica" de Egito Gonçalves ao Surrealismo, conforme apontou Fernando Guimarães. Egito Gonçalves transita também pela poética experimental. No caso específico de Carlos de Oliveira, que soube conciliar sua ligação com os neo-realistas e construir uma obra crítica e esteticamente exemplar, mostra-se o sentido positivo das relações entre poetas e correntes estético-ideológicas, desde que haja uma consciência crítica quanto ao fazer artístico e suas imbricações com a realidade.

O impulso renovador está presente nos diversos núcleos representados pelas revistas literárias e/ou coleções e cadernos de textos poéticos, sendo que, algumas vezes, essas revistas e coleções apresentam um feixe de propostas afins; outras vezes nem chegam a representar um núcleo mais bem definido das várias formulações poéticas daquele momento ${ }^{15}$.

${ }^{14}$ Cf. GUIMARÃES, 1989, p. 59-68.

15 Melo e Castro, em O próprio poético (1973), apresenta um importante quadro das várias revistas existentes naqueles anos, mostrando como se davam as várias formulações dos grupos poéticos e as suas inter-relações a partir da década de 1950. 
Observamos, a partir do estudo de Melo e Castro em O próprio poético (1973), que alguns poetas contribuíram em mais de uma publicação ou núcleo de divulgação e renovação poéticas. Em função da oposição criada pela crítica portuguesa entre o grupo de Poesia 61 e a corrente experimentalista, é importante destacar a participação de Luiza Neto Jorge nos Cadernos de Poesia Experimental, vinda de Poesia 61. Do mesmo modo, pela aproximação que Melo e Castro faz entre o seu livro Queda Livre e as proposições poéticas de Poesia 61, observamos não haver, entre as duas correntes, divergências muito fortes. Gastão Cruz, Fiama H. Pais Brandão e Luiza Neto Jorge, que formaram a base de Poesia 61, receberam influxo também das propostas neo-realistas, as quais foram reelaboradas e ultrapassadas em suas obras, conforme notou Fernando Guimarães. ${ }^{16}$ Herberto Helder, António Aragão, António Ramos Rosa e E. M. de Melo e Castro, escritores com vivências muito diversificadas, juntaram-se e editaram os Cadernos de Poesia Experimental, que contaram, inclusive, com trabalhos de autores do Movimento Surrealista. Do grupo de Távola Redonda derivaram para Tempo Presente António Manoel Couto Viana, Fernando Guedes e Goulart Nogueira. Trata-se de uma revista de inclinação francamente conservadora, como podemos notar no artigo de Goulart Nogueira, que explica a linha editorial da revista. Em síntese, o artigo explicita uma relação entre "tempo presente" e a idéia de atualidade da tradição, aludindo a Eliot em epígrafe na revista. $\mathrm{E}$ a tradição é vista como um universal, um classicismo permanente.

Arnaldo Saraiva, em "A poesia portuguesa nos últimos quinze anos", artigo publicado no Jornal de Letras e Artes, analisa o papel dessas revistas e respectivos grupos durante os anos 50 e início dos 60. Como Castro, Arnaldo Saraiva valoriza, sobretudo, as produções de Árvore e Poesia 61, por oposição ao grupo dos "tavoleiros". Segundo Saraiva, os poetas deste grupo, conforme demonstra na análise de alguns versos de António Manuel Couto Viana, regressavam às fontes líricas tradicionais, retomando temas e problemas de Presença; assim, seus poemas confundiam-se com os de "Cadernos de Poesia no propósito de fazer da poesia uma praça da concórdia humana."17

\footnotetext{
${ }^{16}$ Cf. GUIMARÃES, 1989, p. 67.

${ }^{17}$ Cf. SARAIVA, Jornal de Letras e Artes, 29/06/1966, p. 3.
} 
Ao contemplar esse quadro de renovação e as relações estabelecidas pela corrente experimental, decidimos propor a um de seus principais atores, E. M. de Melo e Castro, a seguinte pergunta: por que a passagem de Décio Pignatari por Lisboa é sempre descrita, nas cronologias portuguesas, como não tendo produzido resultados significantes? Mesmo nos documentos brasileiros, é citada apenas uma entrevista de Décio, publicada no n. 2 da revista Graal, de Lisboa. Depois, cita-se a pequena Antologia da Poesia Concreta brasileira, publicada, juntamente com alguns textos teóricos do concretismo, em 1962, pela Embaixada Brasileira e organizada por Alberto da Costa e Silva. Considerando esses elementos, indagamos a Melo e Castro se Décio Pignatari fizera contato com grupos poéticos atuantes naquele momento. A resposta foi surpreendente. Ele se refere a uma passagem de Décio por Lisboa entre os anos de 58 e 60 - o autor não lembra precisamente a data e não conhecia o brasileiro na época. Pignatari teria encontrado Fernando Guedes, então editor da revista Tempo presente, que publicou importantes textos teóricos e poéticos da Poesia Concreta brasileira - fato nunca mencionado pelos concretos brasileiros em suas inúmeras referências a publicações sobre Poesia Concreta no estrangeiro. A razão disso, segundo Melo e Castro, foi o desconhecimento de Pignatari em relação à real situação vivenciada pelos intelectuais portugueses no contexto do regime Salazarista. Embora Guedes fosse, naquela época, um poeta bem informado e tendo publicado alguns poemas condensados e interessantes, ele era politicamente muito conservador e simpatizante da ditadura salazarista. Além disso, segundo Castro, Fernando Guedes e Manuel Couto Viana, co-responsável pela revista Tempo Presente, utilizaram o fato de os concretos brasileiros haverem publicado no periódico como tentativa de cooptação dos poetas de esquerda, os mesmos que, mais tarde, formariam o grupo da Poesia Experimental Portuguesa ${ }^{18}$.

Eis, então, o motivo por que os poetas do experimentalismo português não frisassem em sua cronologia a passagem do poeta concreto brasileiro. As publicações de Tempo Presente se deram, então, em 1959, ano em que Ana Hatherly publicou o que se considera ser o primeiro poema concreto português. No seu primeiro número (maio/1959), a revista Tempo Presente publicou um estudo introdutório dos próprios

${ }^{18}$ Cf. CASTRO, apud SILVA, 2002, [s.p.]. 
editores sobre a Poesia Concreta, o poema "um tempo/de espaço em espaço", de Augusto de Campos, o "Plano Piloto da Poesia Concreta", e o artigo "A temperatura informacional do texto", de Haroldo de Campos. No segundo número, publicou-se o artigo "Ezra Pound e o futuro da poesia”, de Haroldo de Campos. No número 4, um poema do mesmo poeta.

Nos primeiros e segundo números da revista, Goulart Nogueira, um dos seus fundadores e membro da Comissão Editorial, responsabilizouse por definir o que os editores entendiam como "tempo presente". Através de sua linguagem, percebe-se uma tentativa de inserir os projetos de pacificação estética e política do grupo no contexto das vanguardas que renasciam naqueles anos. Suas palavras dão plena razão a Melo e Castro, como se pode verificar neste excerto. Segundo Nogueira, o significado atribuído à expressão "tempo presente"

(...) é a permanência duma linha profunda, viva, propulsora, uma linha geratriz. É a constância duma tradição, logo duma dinâmica: a tradição nega a estática, assim como nega um movimento sem finalidade. Tradição significa dar vida, renovar. Por isso, a tradição actualiza, quer dizer, age, realiza, torna em acto; e, com a presença, sustenta o tempo, fá-lo hodierno em cada dia de hoje, permite que ela seja capaz de ser o hodierno de amanhã e continue o hodierno de ontem. A tradição mantém a raça, a hereditariedade do tempo, transporta a genes de qualidade humana, garante o universal, actualizando. A tradição é o espírito ${ }^{19}$.

Um espírito desavisado sente ali o eco de uma proposta de vanguarda, ou mesmo uma tentativa de ajustar-se às idéias desenvolvidas por Eliot em "Tradição e talento individual" e, certamente, à filosofia de Hegel. Ao tentar definir o que entende por "espírito", Goulart Nogueira revela, entretanto, uma incapacidade de lidar com o contemporâneo, sacralizando uma idéia de tradição que implica somente apego ao passado. Assim, para ele, a "dialética do espírito" resulta de sua oposição à natureza, que é vista como "deformação monstruosa". Portanto, a superioridade do espírito se daria na superação da degradação e na particularização a que a Natureza submete os objetos.

${ }^{19}$ Cf. NOGUEIRA, In: Tempo Presente, 1959, n. 1, p. 81. 
Como se pode notar, nem é preciso ir muito além no artigo de Goulart Nogueira para verificar o sentido redutor que ele impõe às noções de "tradição", "inovação" e "vanguarda". O autor parece querer tornar excessivamente elástica a noção de "tempo presente", pois só assim poderá apresentar a revista como uma novidade, ainda que esvaziada. Ao contrário do que pensa Goulart Nogueira, o discurso de vanguarda se faz justamente por sua novidade, marginalidade e liberdade, como diz Melo e Castro alertando-nos: "Mas não se tomem estas características textuais como valores absolutos em si próprios. Esses valores só têm razão de ser quando projectados num combate com a realidade, numa práxis portanto." 20

Na sinopse sobre "O movimento da Poesia Concreta", publicada pelos poetas brasileiros, em sua Teoria da Poesia Concreta, os autores indicam, como registro de sua passagem por Portugal, apenas a entrevista de Décio Pignatari em 1956, à revista Graal, dirigida por António Manoel Couto Viana e por seus companheiros da futura Tempo presente. Não há qualquer referência quanto aos textos teóricos e poéticos publicados em 1959 nos números iniciais de Tempo Presente, conforme já dissemos. Isso chama a atenção, porque uma entrevista, em princípio, deveria ser menos importante que a publicação de trabalhos sistemáticos, numa revista de padrão editorial muito bom. O primeiro número de Tempo presente é de maio de 1959, e neste mesmo ano, em setembro, Ana Hatherly publica o primeiro poema concreto português - às vezes erroneamente indicado como sendo o primeiro poema concreto publicado em Portugal. Assim, também não são rigorosamente corretas as informações de Alberto Costa e Silva, que publicou, em 1962, uma antologia da Poesia Concreta, pela Embaixada Brasileira (SEPRO):

O Concretismo brasileiro causou, sim, uma grande impressão em Portugal, e disto sou testemunha e fui, de certa forma, fautor. Os primeiros poemas concretos de Augusto de Campos, Décio Pignatari e Haroldo de Campos foram publicados por Fernando Guedes, na sua revista Verbo. Eles, porém, ganharam a atenção de um maior número de leitores, graças à coletânea $A$ nova poesia brasileira, que organizei em Lisboa em 1960, e a uma plaquette, Poesia Concreta, que, diante do extraordinário interesse pelos nove poetas concretos que figuravam naquele primeiro livro, lancei um ano e meio mais tarde. O êxito foi

${ }^{20}$ Cf. CASTRO, 1987, p. 23. 
enorme entre a gente nova. Creio que essas publicações estimularam os poetas experimentais portugueses a sair à rua, pois, logo em seguida, apareceram Ideogramas de E. M. de Melo e Castro e, pouco depois, as "Brin cadeiras" de Salette Tavares e os poemas visuais de Ana Hatherly. Não teriam os concretos e, antes e depois deles, João Cabral de Melo Neto servido como corretores da excessiva subjetividade e do gosto pela linguagem abstrata de que se ressente grande parte da poesia portuguesa? ${ }^{21}$

Desde 1956, com a entrevista de Décio Pignatari à revista Graal, a Poesia Concreta já começa a ser conhecida em Portugal. Mais relevante, entretanto, é a publicação de textos poéticos e críticos do grupo brasileiro em Tempo Presente (maio, 1959), o que ocorre num momento mais ou menos coincidente com a publicação do primeiro poema concreto de Ana Hatherly. Esse poema saiu no Diário de Notícias, de 17/09/1959, acompanhado do artigo "O idêntico inverso ou o lirismo ultra-romântico e a Poesia Concreta". Logo nas primeiras palavras de seu artigo, Hatherly sintetiza bem as coordenadas da Poesia Concreta, e parece-nos claro que ela tem consciência de que a expressão não é desconhecida do público português. Diz ela: "Reduzir a música a ritmo, o pensamento a esquema, a palavra a substantivo: eis a Poesia Concreta. E a trilogia de toda a criação poética aparece assim mais uma vez demonstrada." 22 A seguir, Ana Hatherly envereda pela discussão dos aspectos que marcam a Poesia Concreta como um "condensado-determinado", explicitando os seus processos de síntese e substantivação da linguagem, suas coordenadas visuais, o equilíbrio rítmico e uma espécie de lirismo que tem "os lábios cerrados", por oposição ao lirismo ultra-romântico:

Se na sua época ultra-romântica o lirismo tocou o extremo do gesticular e das exclamações, o seu idêntico inverso surge agora na forma da Poesia Concreta. Quanto o lirismo ultra-romântico era expansivo, o lirismo concreto é interiorizante: o primeiro gritava, este tem os lábios cerrados $^{23}$.

Apesar de ser considerada pioneira na prática experimental da Poesia Concreta, Ana Hatherly não colabora no primeiro número dos

\footnotetext{
${ }^{21}$ COSTA E SILVA \& BUENO, 1999, p. 29.

${ }^{22}$ Cf. HATHERLY \& CASTRO, 1981, p. 91.

${ }^{23}$ Cf. HATHERLY \& CASTRO, 1981, p. 92.
} 
Cadernos de Poesia Experimental ${ }^{24}$ (1964), idealizados por Herberto Helder e António Aragão, e que contaram com a pronta adesão de E. M. de Melo e Castro. Isso, todavia, não se deve ao fato de se haver interessado episodicamente pela Poesia Concreta e/ou experimental, pois se considerarmos sua obra desde Um ritmo perdido ( 1958), vamos observar um processo individual de radicalização e consciência criativa na atenção para com a linguagem, cujo ápice se dará logo em Sigma (1965) e Eros Frenético (1968). Como declara Ana Hatherly, em entrevista que nos concedeu, dada a heterogeneidade de autores que colaboraram no primeiro número dos Cadernos da poesia experimental, ela esperou para ver como o projeto se desenvolveria, embora tivesse sido convidada para colaborar no primeiro número. Segundo a poeta, o que passou a ser caracterizado mais tarde como um "movimento" de poesia experimental nada mais foi que a publicação dos referidos Cadernos. Em outras palavras, não se pretendeu criar um grupo organizado e nem mesmo um movimento. A própria escolha do nome "Cadernos" seria um indicativo de não haver o desejo de se estabelecer uma delimitação teórica precisa com a qual pudessem definir uma ação coerente de grupo. Quanto à vastidão do conceito, declara Ana Hatherly, na entrevista que nos concedeu, ser o conceito de experimentalismo muito vasto, embora justificado no caso português, pois, além de não identificar um grupo coeso, no que designavam de experimental estava contida a experiência

${ }^{24}$ Tratava-se, não de brochuras, mas de uma publicação em formato A4 duplo, em folhas soltas e dobráveis, de modo a formarem-se páginas na dimensão de 15 x 29,5 cm. No número 1, colaboraram António Aragão, António Barahona da Fonseca, António Ramos Rosa, E. M. de Melo e Castro, Herberto Helder, Salette Tavares. O número contou ainda com uma antologia: Luís de Camões (Os chamados disparates da Índia), Ângelo de Lima (Edd'ora addio... - mia soave!...), Mário Cesariny de Vasconcelos (Ditirambo), Emilio Villa (Carta para Ruggero Jacobbi) e Quirinus Kuhlman (O XLI beijo de amor). O número 2 contou com poemas de Herberto Helder, Ana Hatherly, Luíza Neto Jorge, José Alberto Marques, E. M. de Melo e Castro, Herberto Helder, António Aragão, António Barahona da Fonseca, José Alberto Marques, Jorge Peixinho (Música e notação), Henri Chopin, Ian Hamilton Finlay, Haroldo de Campos, Emilio Villa, Mike Weaver, Edgard Braga, Mário Diácono, Pedro Xisto, Pierre Garnier, Sallete Tavares e Álvaro Neto. 
com a poesia concreta e as relações com outros movimentos europeus, em especial a Inglaterra, onde ela e Melo e Castro possuíam relações mais estreitas.

Percebemos aí que o fenômeno da Poesia Concreta, seja européia ou seja brasileira, contagiava o experimentalismo português, assim como, de certa forma, suas práticas e experiências com ele se confundiam. Aos poucos, os autores que permanecem unidos em torno do experimentalismo poético foram produzindo a teoria do movimento (em parte reunida nos documentos da Po.ex, 1981). Houve, contudo, uma única tentativa de lançamento de um Manifesto, esboçado por Melo e Castro, mas que não vingou. Este esboço está publicado no livro PO.EX - Textos teóricos e documentos da Poesia Experimental Portuguesa (1981), organizado por Ana Hatherly e E. M. de Melo e Castro. À exceção de algumas exposições, de happenings, de entrevistas e de alguns textos críticos veiculados em jornal e depois incorporados à produção ensaística dos autores, a Poesia Experimental existiu, de fato, na produção criativa de seus autores. Além dos Cadernos da poesia experimental, que duraram dois números (1964 e 1966), houve uma outra única produção coletiva, que se intitulou "Operação 1" e "Operação 2", lançadas, simultaneamente, em exposição na Galeria Quadrante, de Lisboa. O formato era o de cartazes, de 51,5 x $36 \mathrm{~cm}$, e contou com a colaboração de António Aragão, Ana Hatherly, E. M. de Melo e Castro, José Alberto Marques e do brasileiro Pedro Xisto, que publicou "4 epithalamia". A "Operação 2" resultou do livro "Estruturas poéticas", de Ana Hatherly, hoje incluídas em seu Um Calculador de Improbabilidades (2001).

$\mathrm{Na}$ ótica de Hatherly, isso se deveu provavelmente à heterogeneidade de poetas e de práticas poéticas que se reuniram nos Cadernos; por isso, alguns simplesmente se afastaram e outros romperam com o movimento, como foi o caso de Herberto Helder. Porém um fator que contribuiu para a aproximação entre vários dos poetas fundadores da Poesia Experimental Portuguesa pode ter sido algo semelhante ao que levou Helder a ser um de seus propositores: a necessidade de se obter novos efeitos poéticos e a saída de um ciclo esgotado. Maria de Fátima Marinho, refletindo sobre a trajetória de Helder, sugere que essa foi uma opção do escritor:

Foi precisamente porque chegou à conclusão de que nos livros anteriores se limitava a "mover[-se] em círculos sobre uma linguagem 
esgotada", que Herberto Helder passou a usar novas técnicas visuais e verbais, passou a experimentar no sentido mais radical da palavra ${ }^{25}$.

Sobre o afastamento de Herberto Helder da poesia experimental, pode-se entender, conforme o texto de Marinho, que Helder se aproxima ou se afasta desta ou daquela tendência conforme uma necessidade estética. Esta não é, entretanto, a opinião de Melo e Castro que afirma ter sido uma ruptura violenta, com publicação de uma carta nos jornais da época. Durante nossa entrevista, este fato não foi confirmado por Ana Hatherly, que era a pessoa mais próxima de Herberto Helder, embora tenha afirmado guardar uma carta do autor, justificando as razões de seu afastamento. Também, segundo Melo e Castro, desta vez confirmado por Hatherly, houve uma discussão a respeito de um manifesto redigido por António Ramos Rosa, que deveria ser publicado no segundo Caderno. Esse "manifesto", entretanto, nunca chegou a ser publicado, porque, após ter sido lido por colaboradores, foi recusado por Salette Tavares. Segundo Melo e Castro, em nossa entrevista, Tavares, "à frente de cada alínea, escreveu 'a contrária também é verdadeira'”. Ainda, segundo Melo e Castro, António Ramos Rosa ficou ofendidíssimo e não houve manifesto. Deste modo, nunca houve reunião para discutir o manifesto, que, entretanto, foi lido por todos os colaboradores. Após esse episódio, teria ocorrido o afastamento de Herberto Helder. É preciso, entretanto, não esquecer que alguns poemas de Herberto Helder foram publicados no segundo número dos Cadernos, que só saiu em maio de 1966, quando era previsto para 1965. Neste ano de 1965, ainda encontramos contribuições de poemas visuais de Herberto Helder para a Exposição Visopoemas, organizada por Melo e Castro na Galeria Divulgação, em 2 de janeiro e, depois, na Antologia da Poesia Concreta em Portugal, organizada pelo mesmo e por José Alberto Marques, em 1973.

Os fatos a que nos referimos demonstram a dificuldade de constituição de um movimento coeso e afinado no Portugal dos anos 60. Além disso, era impossível um debate aberto sobre as dissensões existentes entre os membros do grupo, já que isso afetaria profundamente sua sobrevivência, dado o contexto político de exceção vivido em Portugal. Assim, conforme explicita Melo e Castro, seria impossível responder publicamente à "carta" em que Herberto Helder teria

\footnotetext{
${ }^{25}$ MARINHO, 1982, p. 91.
} 
apresentado discordância em relação ao movimento da poesia experimental nos jornais:

Eu tive uma resposta preparada para o Herberto Helder, mas não a publiquei, porque nós iríamos iniciar uma discussão pública que, invariavelmente, cairia em assuntos políticos e isso iria ter efeitos negativos para todos. Não escrevi, e combinei isso com António Aragão, uma pessoa com quem eu sempre me dei muito bem; com quem tive sempre uma consonância quer estética, quer humana, quer poética. Nós iríamos de certo modo enfraquecer a nossa projeção, porque a dissidência do Helder foi comemorada. O melhor era não dizer nada ${ }^{26}$.

A polemizar com Helder nos jornais, afirmou-nos Melo e Castro que preferiu uma resposta teoricamente fundamentada, que foi seu ensaio "Proposição 2.01", incluído depois em Opróprio poético (1973). De acordo com o poeta, somente após o segundo número dos Cadernos da Poesia Experimental começa a se consolidar essa prática experimentalista. Em termos de movimento, porém, Ana Hatherly recorda que a poesia experimental representava também uma ação política no quadro da época:

Só ao longo do tempo é que [a po.ex] conseguiu definir-se como um movimento, com características muito bem definidas: a primeira e importantíssima era o fato de ser uma ligação ao movimento internacional, num momento em que Portugal vivia sob o fascismo e Salazar havia posto o distintivo "Orgulhosamente sós". Portanto, era um movimento transgressor, como qualquer movimento de vanguarda no século XX, mas tinha essa particularidade que era a de estar sob um regime altamente repressivo que proibia todos os contatos (tinha a censura local) e censurava os contatos com movimentos internacionais. Ora esse movimento internacional era evidentemente um movimento revolucionário em escala internacional. Eram os anos 60 e nem vale a pena dizer mais nada. Nós, integrados nesse movimento internacional, estávamos a ser agressores para o regime vigente. Isso acrescentou ao nosso movimento, às nossas pesquisas, ao nosso trabalho uma dimensão política específica. Não era só ser anti-establishment. Era especificamente [compor] o novo establishment mundial, mas principalmente contra o establishment nacional. ${ }^{27}$

\footnotetext{
${ }^{26}$ CASTRO, Apud SILVA, 2002.

${ }^{27}$ HATHERLY, Apud SILVA, 2002.
} 
Durante todo esse período, porém, os poetas enfrentaram críticas cerradas nos periódicos portugueses, como foi o caso exemplar de uma polêmica em torno da publicação de A poligonia do soneto (1964), sendo o alvo predileto o "soneto soma $14 \mathrm{x}$ ", construído apenas com linguagem numérica. Escandalizadas, ficaram, em 1964, revistas como Seara Nova, de tendência esquerdista, em seus números 1421, 22 e 23, que publicou nota não assinada sobre o livro, na qual afirmava tratarem-se de divertimentos de Melo e Castro, com que talvez pretendera escandalizar o leitor ou "preparar armadilhas para críticos 'formalmente reacionários". Da mesma maneira, porém mais respeitosamente, O tempo e o modo faz publicar uma resenha assinada por José Bento, que procura à luz da própria teoria da poesia experimental demonstrar que os poemas são meros jogos formais. Compara, por exemplo, alguns sonetos "transcendentalizantes" de autores consagrados portugueses com as "experiências" de Melo e Castro, para concluir na esterilidade da pesquisa de linguagem na poesia experimental. Um soneto como o conhecido "soma 14x" é comparado a um simples aglomerado de algarismos, como numa fita de máquina calculadora. A essa acusação, Melo e Castro responde na edição subseqüente da revista com o seguinte raciocínio:

O soneto Soma 14x tem uma construção dupla, pois, por um lado, ele não é mais que o esqueleto não lingüístico de um soneto normal em que os fonemas e as imagens (sinais poéticos) foram substituídos por sinais aritméticos, estando estes sujeitos às mesmas leis de um soneto vulgar. Por outro lado, procurou-se um conteúdo metafórico genérico de base aritmética e assim os algarismos de cada verso somam 14 menos o último que soma 28 ( $14 \times 2$ ). Assim este esqueleto de soneto aponta para uma representação matemática de todos os sonetos possíveis dentro de uma idéia talvez arquétipica de unidade estrutural de perfeição poética em 14 versos, mas no entanto aberta a todas as possibilidades, destruições, negações e também renascimentos... pois se trata de uma forma abstrata matemática $(. . .)^{28}$

O problema que aqui se coloca é o mesmo relativo à leitura de qualquer poema moderno. Não há chave que possa servir ao seu leitor, e é preciso que ele participe re-construindo o poema, despindo-se de

${ }^{28}$ Cf. CASTRO, In: O tempo e o modo, n. 19, 1994, p. 202-3. 
preconceitos. No caso de José Bento, seu artigo "Poligonia do Soneto", publicado no no 18 de O tempo e o modo, parece simular um pacto com os poemas de Castro, ao propor uma análise dentro dos pressupostos teóricos da poesia experimental. O autor, no entanto, não abriu mão dos valores que orientam um crítico apegado à tradição. Com isso, ele aproxima os sonetos de Melo e Castro daqueles sonetos portugueses já suficientemente digeridos pela crítica tradicional, exclusivamente, para mostrar o quanto os sonetos de Castro ficam a dever ao passado. Especificamente no caso do soneto "Soma 14x", o ponto de tensão mais evidente é a mudança do código lingüístico para o matemático. Portanto, a análise de José Bento sobre Poligonia e sobre "Soma 14x", em especial, indica pouca disposição para aceitar essa mudança de códigos, isto é, parece-nos que ele só considera o soneto se este for feito com palavras de nobre extração, e principalmente que seja realizado com palavras. Assim, escapa-lhe o fato de que, ao recusar o lingüístico e glosar o próprio formalismo do soneto, o poema de Melo e Castro pode sugerir que a forma virou fôrma. Quer dizer, o soneto já não diz nada como forma, pois foi transformado em fórmula pelas convenções poéticas. Como bem disse Alberto Pimenta, "catorze versos de dez sílabas bem contadas e medidas não é bastante para dar razão poética ao discurso"29.

Apesar dos choques com o público amante de uma poesia mais comportada, ligada ao discurso transcendental e valorizada pelos veículos de divulgação e cultura, a poesia experimental constituiu-se como movimento e produziu sua teoria. Nos textos reunidos na Po-ex (1981), verificamos que, no início, seus idealizadores buscaram inserir a Poesia Experimental Portuguesa no conjunto daquelas produzidas pelo movimento internacional. Em carta de janeiro de 1964, Pierre Garnier louva a integração do experimentalismo português no movimento internacional, ao concordarem os poetas portugueses em adotar o rótulo "espacialismo" em suas produções poéticas ${ }^{30}$. Em 1964, já nos números 32 e 33, de Le Lettres, revista dirigida por Garnier, são publicados poemas experimentais portugueses e aparecem referências sobre o movimento em Portugal.

\footnotetext{
${ }^{29}$ Cf. PIMENTA, 1995, p. 89.

${ }^{30}$ Cf. HATHERLY \& CASTRO, 1981, p. 219.
} 
Em parte, depois do 25 de Abril de 1974, atenua-se a visão que uma grande parcela dos leitores e da própria crítica tinham da Poesia Experimental como movimento político de reação à ditadura salazarista. Melo e Castro chega mesmo a dizer que muitos dos críticos à corrente diziam que a Poesia Experimental acabara. Talvez, como movimento, isso possa ser constatado, mas não como experiência de linguagem e de abertura, pois esta permanece presente na obra dos poetas que foram os protagonistas centrais da Poesia Experimental e que lhe deram consistência, como podemos constatar na poesia de Melo e Castro, Ana Hatherly, Salette Tavares, Herberto Helder, entre outros, e na produção crítica dos dois primeiros. De certa forma, esse sentimento de que a Poesia Experimental foi principalmente um movimento político se deve ao papel que a própria poesia desempenhou durante os anos de repressão, como mostra Gastão Cruz, considerando uma parcela dos textos mais criativos na virada dos anos 80:

Suponho que o fenômeno que referi atrás, uma certa desertificação da área poética [na década de 80], terá não pouco a ver com os aspectos políticos e sociais da fase que se vive no nosso país.

Durante a ditadura, a poesia foi sempre, mesmo quando menos comprometida com o processo histórico, um fortíssimo símbolo de resistência e de luta pela liberdade ('poesia, liberdade livre' lhe chamou António Ramos Rosa), o que lhe dava uma capacidade de afirmação realmente poética (quer se tratasse de O amor em Visita de Herberto Helder ou de O Grito Claro de Ramos Rosa) que directa ou indirectamente se relacionava sempre com a recusa do repugnante sistema de valores que pesava sobre uma nação inteira ${ }^{31}$.

Joaquim Manuel Magalhães, refletindo sobre a poesia pós-25 de abril, chama a atenção para algumas das expectativas frustradas sobre esse momento, em que apareceriam as obras não publicadas devido à repressão fascista assim como a difusão daquelas obras dos que haviam sido forçados ao exílio. Ambas as promessas não se realizaram, embora Magalhães atribua parte do problema à substituição da censura que se valia da masmorra (a do regime antidemocrático) pela censura do capitalismo democrático, que se serve da mais-valia. Assim, para o crítico, o principal desta questão não foi publicar o que era suposto existir, mas,

${ }^{31}$ CRUZ, 1999, p. 219. 
principalmente, o desviar a realidade portuguesa para um outro contexto, sujeitá-la a uma interação de novos feixes situacionais. Neste sentido, o crítico reconhece o papel desempenhado pela ação criativa de Poesia 61 e Poesia Experimental, principalmente "no dessoramento processual da poesia de compromisso ou do lirismo tradicionalista que viera a ocupar posições dominantes ao longo dos anos 50"32.

Dado esse contexto em que se processou a Poesia Experimental Portuguesa, torna-se visível a importância da Poesia Concreta em Portugal, tendo sido o movimento português o responsável pela entrada da Poesia Concreta na Inglaterra, conforme registram os organizadores da Po-Ex, antologia crítica do movimento realizada por Melo e Castro e Ana Hatherly.

Para finalizarmos, é preciso destacar que aqui, no Brasil, como em Portugal, tais movimentos foram importantes na retomada do espírito renovador das respectivas tradições modernistas, trazendo para um nível mais concreto o diálogo das forças criativas de seu tempo, num intercâmbio internacional jamais visto. No plano de suas respectivas realidades nacionais, foram também importantes, não só pela polêmica suscitada por suas ações, capazes de sacudir o ambiente tépido de então, mas também por comportarem uma atitude política de abertura. Mesmo que muitos escritores e críticos neguem sua influência no cenário atual, dificilmente se pode esquecer essa sua lição de abertura estética e vivencial, capazes de recuperar o vigor do passado e de projetar futuros.

\section{Referências Bibliográficas}

CASTRO, E. M. de Melo e. As vanguardas na poesia portuguesa do século XX. Lisboa: Instituto de Cultura e Língua Portuguesa, 1987. (Biblioteca Breve; 52) CASTRO, E. M. de Melo e. Opróprio poético-Ensaio de revisão da literatura portuguesa atual. São Paulo: Edições Quíron, 1973.

CASTRO, E. M. de Melo e; MARQUES, José Alberto. Antologia da poesia concreta em Portugal. Lisboa: Assírio \& Alvim, 1973.

32 MAGALHÃES, 1981, p. 255. 
COSTA E SILVA, Alberto da; BUENO, Alexei. Antologia da Poesia Portuguesa Contemporânea - Um panorama. Rio de Janeiro: Lacerda Editores, 1999.

HATHerly, Ana; CASTRO, E. M. de Melo e. Po.EX: textos teóricos e documentos da poesia experimental portuguesa. Lisboa: Moraes, 1981.

GUIMARÃES, Fernando. A poesia contemporânea e o fim da modernidade. Lisboa: Editorial Caminho, 1989 (Col. Estudos da Literatura Portuguesa).

MAGALHÃES, Joaquim Manuel de. "Alguns aspectos dos últimos anos". In: MAGALHÃES, Joaquim Manuel de. Os dois crepúsculos. Lisboa: A regra do jogo, 1981. p. 251-276.

MARINHO, Maria de Fátima. Herberto Helder - a obra e o homem. Lisboa: Editora Arcádia, 1982.

NOGUEIRA, Goulart. "Tempo presente”. In: Tempo presente, 1959, n.1, p. 81-83.

O TEMPO E OMODO- Revista de pensamento e acção. Lisboa: Livraria Morais Editora, n. 19, set/1964, p. 202-7

PIMENTA, Alberto. O silêncio dos poetas. Lisboa: Edições Cotovia, 2003.

PIMENTA, Alberto. A magia que tira os pecados do mundo. Lisboa: Edições Cotovia, 1995.

SARAIVA, Arnaldo. A poesia portuguesa nos últimos quinze anos. Jornal de Letras e Artes, 29/06/1966, p. 3 e 15.

SILVA, Rogério Barbosa da. Entrevista com E. M. de Melo e Castro. Lisboa: [s.n.], 2002 (mimeo).

SILVA, Rogério Barbosa da. Entrevista com Ana Hatherly. Lisboa: [s.n.], 2002 (mimeo).

SOUSA, Carlos Mendes; RIBEIRO, Eunice. "Poesia Experimental: 'Que não há novíssima poesia”". In: . Antologia da Poesia Experimental Portuguesaanos 60-anos 80. Coimbra: Ângelus Novus, 2004. p. 15-63.

REVISTA TEMPO PRESENTE. Lisboa: Editora Verbo, n. 1, 2, 3, e 4, mai a ago/ 1959. 


\section{Resumo}

O presente trabalho estuda a construção do movimento da Poesia Experimental Portuguesa, que teve um papel importante na renovação estética na literatura dos anos 60, contribuindo para um debate internacional em torno dos movimentos de poesia experimental e, a partir deste mesmo debate, propondo um caminho de liberdade criativa, frente ao quadro político reinante em Portugal. Destacamos, neste contexto, a importante participação da Poesia Concreta brasileira como estímulo a esta abertura estética.

\section{Abstract}

This work studies the construction of the Portuguese Experimental Poetry that had a great part in the aesthetic renewal in the literature of the sixties, contributing to an international debate around the movements of experimental poetry and, because of this, proposing an opening for the creative freedom, in the presence of the political and cultural situation in Portugal in these years. We highlighted, in this context, the important participation of the Brazilian Concrete Poetry as incentive for this aesthetic opening. 